Article

\title{
Improved hydrogen evolution on glassy carbon electrode modified with novel Pt/cetyltrimethylammonium bromide nanoscale aggregates
}

\author{
Jahan-Bakhsh Raoof a,*, Sayed Reza Hosseini ${ }^{b}$, Seyedeh Zeinab Mousavi-Sani a \\ a Electroanalytical Chemistry Research Laboratory, Department of Analytical Chemistry, Faculty of Chemistry, University of Mazandaran, \\ 47416-95447, Babolsar, Iran \\ b Nanochemistry Research Laboratory, Faculty of Chemistry, University of Mazandaran, 47416-95447, Babolsar, Iran
}

\section{A R T I C L E I N F O}

Article history:

Received 26 June 2014

Accepted 11 August 2014

Published 20 February 2015

Keywords:

Cetyltrimethylammonium bromide

Impedance spectroscopy

Hydrogen evolution

Platinum particle
A B S T R A C T

A novel, cost-effective, and simple electrocatalyst based on a Pt-modified glassy carbon electrode (GCE), using cetyltrimethylammonium bromide (CTAB) as a cationic surfactant, is reported. Amphiphilic CTAB molecules were adsorbed on GCE by immersion in a CTAB solution. The positively charged hydrophilic layer, which consisted of small aggregates of average size less than $100 \mathrm{~nm}$, was used for accumulation and complexation of $\left[\mathrm{PtCl}_{6}\right]^{2-}$ anions by immersing the electrode in $\mathrm{K}_{2} \mathrm{PtCl}_{6}$ solution. The modified electrode was characterized using scanning electron microscopy, energy-dispersive X-ray spectroscopy, impedance spectroscopy, and electrochemical methods. The electrocatalytic activity of the Pt particles in the hydrogen evolution reaction (HER) was investigated. The results show that the CTAB surfactant enhances the electrocatalytic activity of the Pt particles in the HER in acidic solution.

(C) 2015, Dalian Institute of Chemical Physics, Chinese Academy of Sciences. Published by Elsevier B.V. All rights reserved.

\section{Introduction}

The hydrogen evolution reaction (HER) is one of the most widely studied reactions in electrochemistry and is important for the development of water electrolysis and fuel cell technology [1-4]. The production of electrocatalysts is still the focus of the development of hydrogen-based fuel cell systems as power sources for emission-free electric vehicles. Pt is an ideal catalyst for electrochemical production of hydrogen from acidic aqueous solutions. However, Pt is extremely expensive, therefore reducing the amount of $\mathrm{Pt}$ used in processes where it is essential is beneficial.

The search for new and less expensive alternative materials for the HER is a topic of current interest. The dispersion of Pt microparticles in polymer matrixes [5,6] and the use of less expensive metal materials such as tungsten [7], titanium [8], tantalum [9], and aluminum [10] are common procedures for reducing the cost of anode materials in industrial electrochemical application. However, the synthesis of Pt particles can be difficult.

Surfactants (surface active agents) are molecules that form thermodynamically stable nanoscale aggregates in solution and at interfaces. Surfactant self-assembly in solution has been investigated theoretically and experimentally, partly because of the importance of such ordered templates in the synthesis of nanometer- to micron-scale structures with controlled dimensions. Because of the amphiphilic structures of surfactants, these molecules can be adsorbed on interfaces and surfaces. Cetyltrimethylammonium bromide (CTAB), which is a cationic surfactant, has been widely used in electrochemistry, including

*Corresponding author. Tel: +98-11-35302392; Fax: +98-11-35302350; E-mail: j.raoof@umz.ac.ir 
electroanalytical chemistry [11-16], to change the electrochemical process through adsorption at interfaces or aggregation into a supramolecular structure.

The construction of Pt-modified porous electrodes is difficult, therefore electrodes modified with Pt particles fabricated by novel and simple methods, in which Pt is deposited directly on the substrate at room temperature, are useful. Recently, we reported Pt-modified electrodes consisting of n-Au@Pt/SAM/ GFE [17], Pt/n-Cu foam/Cu [18], and n-Pt/Cu-P(8-HQ)/glassy carbon electrode (GCE) [19], which catalyze the HER in acidic media. A literature survey showed that there is no report as yet on the use of CTAB, a commercially available surfactant, for accumulation of Pt ions on a GCE surface. In this paper, we report the HER performance on a Pt-modified GCE as an electrocatalyst in $\mathrm{H}_{2} \mathrm{SO}_{4}$ solution.

\section{Experimental}

\subsection{Materials and instrumentation}

The solvent used was double-distilled water. CTAB (>98\%) and $\mathrm{K}_{4} \mathrm{Fe}(\mathrm{CN})_{6}(>99 \%)$ were obtained from Merck. $\mathrm{H}_{2} \mathrm{SO}_{4}$ (>98\%), $\mathrm{K}_{2} \mathrm{PtCl}_{6}, \mathrm{KCl}(>99 \%)$, and $\mathrm{K}_{3} \mathrm{Fe}(\mathrm{CN})_{6}(>99 \%)$ obtained from Fluka were analytical grade.

Electrochemical measurements were performed using a potentiostat and galvanostat (Autolab, PGSTAT30, Eco Chemie, the Netherlands), with FRA software for impedance spectroscopy and GPES software for cyclic voltammetry. All measurements were performed in a three-electrode cell. The threeelectrode system consisted of a saturated calomel electrode (SCE) as the reference electrode, a Pt wire as the auxiliary electrode, and a glassy carbon disk (radius $0.1 \mathrm{~cm}$ ) as the working electrode substrate. Surface morphology observations and elemental analysis of the deposits were performed using a scanning electron microscope (SEM; VEGA-Tescan, Razi Metallurgical Research Center) equipped with an energy-dispersive X-ray spectrometer (EDS).

\subsection{Electrode modification}

Prior to modification, the GCE was polished carefully with alumina slurries on a polishing cloth to a mirror finish, and then ultrasonically cleaned for $2.0 \mathrm{~min}$ in ethanol. The electrode was rinsed thoroughly with distilled water. The Pt deposits were prepared as follows. The clean GCE was placed in a well-stirred CTAB solution (3.0 mmol/L). After $2.0 \mathrm{~min}$ (optimum time), the obtained CTAB-GCE was rinsed with distilled water, and then the electrode was immersed in $\mathrm{K}_{2} \mathrm{PtCl}_{6}$ solution (5.0 mmol/L) for $5.0 \mathrm{~min}$ (optimum time). The electrode was then immersed in $\mathrm{KCl}$ solution $(0.1 \mathrm{~mol} / \mathrm{L})$ while the electrode potential was swept between -0.70 and $1.10 \mathrm{~V}$ vs the SCE. An unmodified GCE was prepared in the same way but without adding CTAB, for comparison, and is denoted by Pt/GCE. For the HER experiments, the potentials were cycled between 0.0 and $-0.5 \mathrm{~V}$ vs the SCE at $v=50 \mathrm{mV} / \mathrm{s}$. In the presence of CTAB, a positively charged hydrophilic film formed at the electrode surface. This hydrophilic layer increases the local concentration of the $\left[\mathrm{PtCl}_{6}\right]^{2-}$ anions at the surface. It was assumed that immersion of the CTAB-GCE in a Pt salt solution leads to formation of a complex containing both $\mathrm{Pt}$ and $\mathrm{CTA}^{+}$ions. All experiments were performed at ambient temperature. The effective surface area of the GCE was calculated using cyclic voltammetry at different potential scan rates with $\mathrm{K}_{3} \mathrm{Fe}(\mathrm{CN})_{6}(5.0$ $\mathrm{mmol} / \mathrm{L})$ as a probe in $\mathrm{KCl}$ solution (0.1 mol/L). The Randles-Sevcik formula [20] was used. The effective surface area of the GCE was $0.028 \mathrm{~cm}^{2}$. The actual Pt surface area $\left(A_{\mathrm{r}}\right.$, $\mathrm{cm}^{2}$ ) of the Pt catalyst was estimated from the integrated charges in the hydrogen adsorption region, as $A_{\mathrm{r}}=Q_{\mathrm{H}} / Q_{\mathrm{O}}$, where $Q_{\mathrm{O}}$ is commonly taken as $0.21 \mathrm{mC} / \mathrm{real} \mathrm{cm}^{2}$, and $Q_{\mathrm{H}}$ is the charge consumed for hydrogen adsorption. The calculated $A_{\mathrm{r}}$ values for Pt/CTAB-GCE and Pt/GCE were 0.052 and $0.035 \mathrm{~cm}^{2}$,

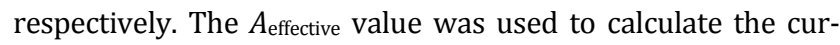
rent density, except for comparison with the HER.

\section{Results and discussion}

\subsection{Electrochemical properties of CTAB-GCE}

The cyclic voltammogram of the $\mathrm{K}_{4} \mathrm{Fe}(\mathrm{CN})_{6}$ solution at the surface of the bare GCE gives the anodic and corresponding cathodic peak of the Fe(CN)6 $6^{3-/ 4-}$ redox couple (Fig. 1(a)(1)). The voltammetric response at the CTAB-GCE surface is better, reflected by enlargement of the peak currents and a decline in the potential difference (Fig. 1(a)(2)). CTAB can form a surface
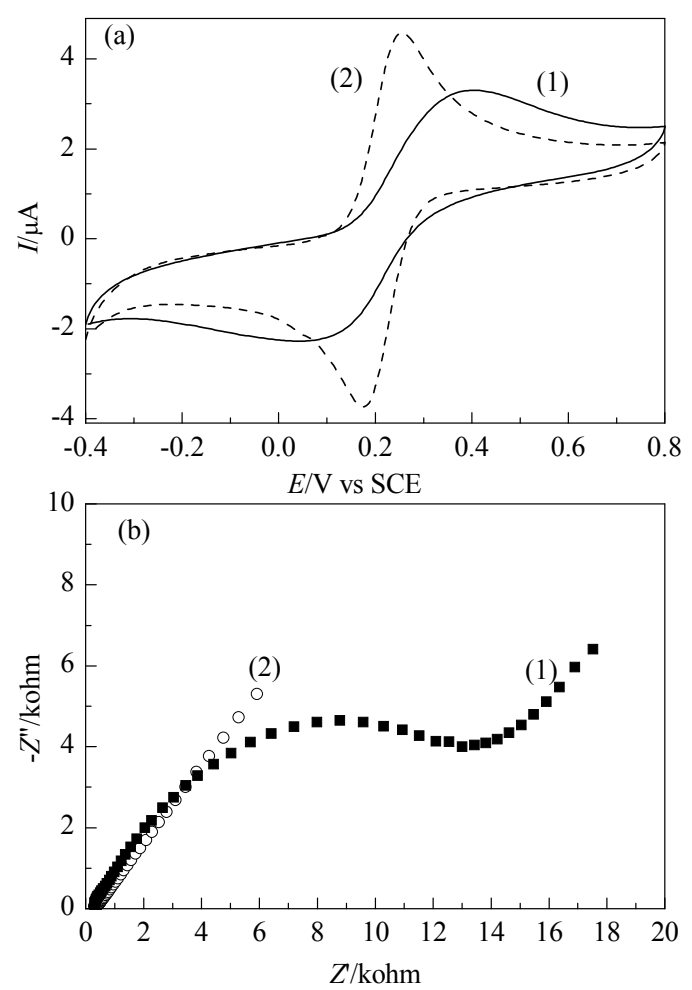

Fig. 1. (a) Cyclic voltammograms of $\mathrm{K}_{4} \mathrm{Fe}(\mathrm{CN})_{6}(1.0 \mathrm{mmol} / \mathrm{L})$ in $\mathrm{KCl}$ solution (0.1 mol/L) at (1) bare GCE and (2) CTAB-GCE at $v=0.05 \mathrm{~V} / \mathrm{s}$; (b) Nyquist plots $\left(Z_{\mathrm{im}}\right.$ vs $Z_{\mathrm{re}}$ ) of faradaic impedance measurements performed at (1) bare GCE and (2) CTAB-GCE in the presence of solution $(1.0 \mathrm{mmol} / \mathrm{L})$ of $\mathrm{K}_{3} \mathrm{Fe}(\mathrm{CN})_{6} / \mathrm{K}_{4} \mathrm{Fe}(\mathrm{CN})_{6}=1$ mixture, with biasing of working electrode at $0.21 \mathrm{~V}$. 
complex with $\mathrm{Fe}(\mathrm{CN})_{6}{ }^{4-}$ through electrostatic interactions and can also be adsorbed at the interface between the hydrophobic surface and the aqueous solution.

The CTAB adsorptive behavior was further investigated using electrochemical impedance spectroscopy (EIS). The EIS results were in agreement with the cyclic voltammetry results. For diffusive species, the EIS includes a semicircle and a linear part; the semicircle part at high frequencies corresponds to the electron-transfer-limited process, and the linear part at low frequencies corresponds to the diffusion process. Figure 1(b)(1) shows the EIS results for the bare GCE; it consists of a high-frequency semicircle and a low-frequency straight line. However, the straight line for the CTAB-GCE surface is different from that for the bare GCE (Fig. 1(b)(2)). This shows that the electron-transfer process was facilitated by the presence of a positive layer at the electrode surface. The charge-transfer resistance is therefore unimportant in relation to the Warburg impedance.

\subsection{Surface morphology and elemental analysis}

Figure 2(a) shows the morphology of the bare GCE after cleaning. The figure shows that there are some defects on the surface caused by electrode polishing. From the above discussion, it is conceivable that the GCE surface morphology is affected by CTAB adsorption. The SEM image of the CTAB-GCE
Table 1

Elemental analytical data for CTAB-GCE and Pt/CTAB-GCE obtained using EDS.

\begin{tabular}{lccrrr}
\hline \multirow{2}{*}{ Element } & \multicolumn{2}{c}{ CTAB-GCE } & & \multicolumn{2}{c}{ Pt/CTAB-GCE } \\
\cline { 2 - 3 } \cline { 5 - 6 } & $\mathrm{Wt} \%$ & $\mathrm{At} \%$ & & $\mathrm{Wt} \%$ & $\mathrm{At} \%$ \\
\hline $\mathrm{C}$ & 71.99 & 90.13 & & 49.66 & 66.87 \\
$\mathrm{Pt}$ & 0.00 & 0.00 & & 2.53 & 0.21 \\
$\mathrm{Br}$ & 0.08 & 0.01 & & 0.07 & 0.01 \\
$\mathrm{~N}$ & 5.98 & 6.42 & & 18.19 & 21.01 \\
$\mathrm{O}$ & 2.03 & 1.91 & & 9.85 & 9.96 \\
$\mathrm{Cl}$ & 0.00 & 0.00 & & 0.86 & 0.39 \\
$\mathrm{Au}$ & 19.92 & 1.52 & & 18.83 & 1.55 \\
Total & 100 & 100 & & 100 & 100 \\
\hline
\end{tabular}

shows small aggregates of average size less than $100 \mathrm{~nm}$; these are beneficial for the accumulation of $\left[\mathrm{PtCl}_{6}\right]^{2-}$ anions (Fig. 2(b)). Figure 2(c) shows that the Pt/CTAB-GCE is composed of small Pt particles. EDS was used to determine the surface compositions of the CTAB-GCE and Pt/CTAB-GCE (Fig. 3). The elemental analytical data obtained using EDS are listed in Table 1 . The EDS results show that $\mathrm{N}$ and $\mathrm{O}$ were the major elements. $\mathrm{C}$ was derived from the GCE, and $\mathrm{N}$ and $\mathrm{Br}$ come from the surfactant. It should also be noted that the Pt loading in the case of the Pt/CTAB-GCE is about $2.5 \mathrm{wt} \%$. Specimens are usually coated with an ultra-thin coating of electrically conducting material, deposited either by low-vacuum sputter-coating or high-vacuum evaporation. Gold is the conductive material most
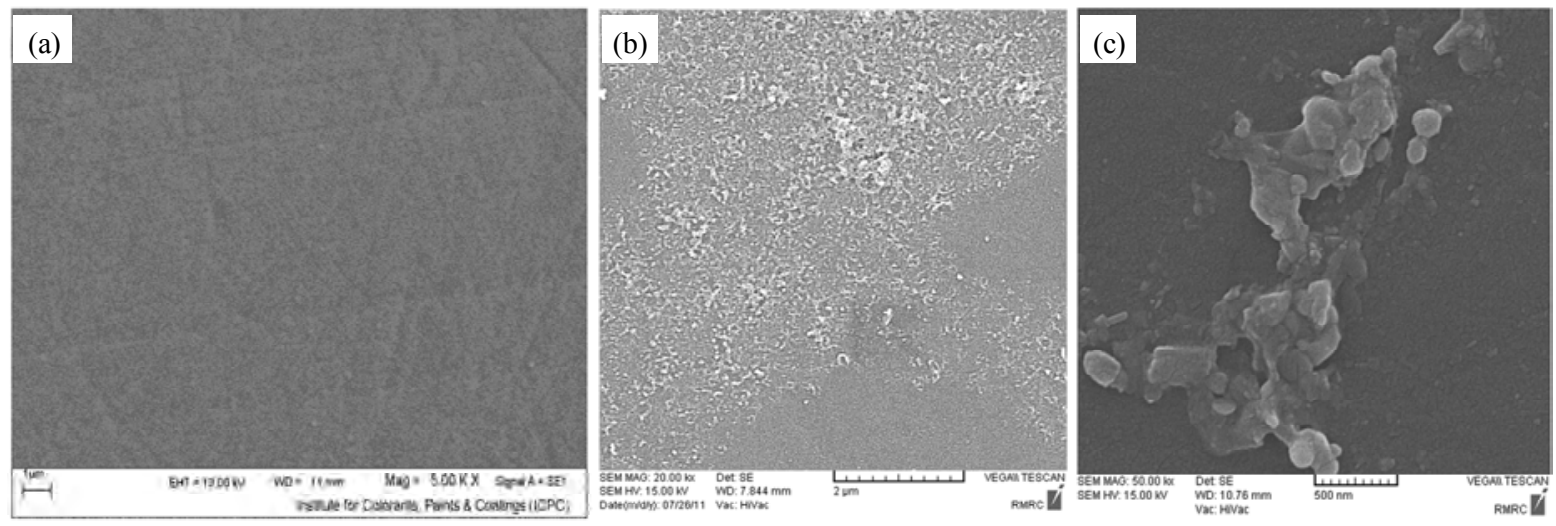

Fig. 2. SEM images of (a) bare GCE, (b) CTAB-GCE, and (c) Pt/CTAB-GCE.
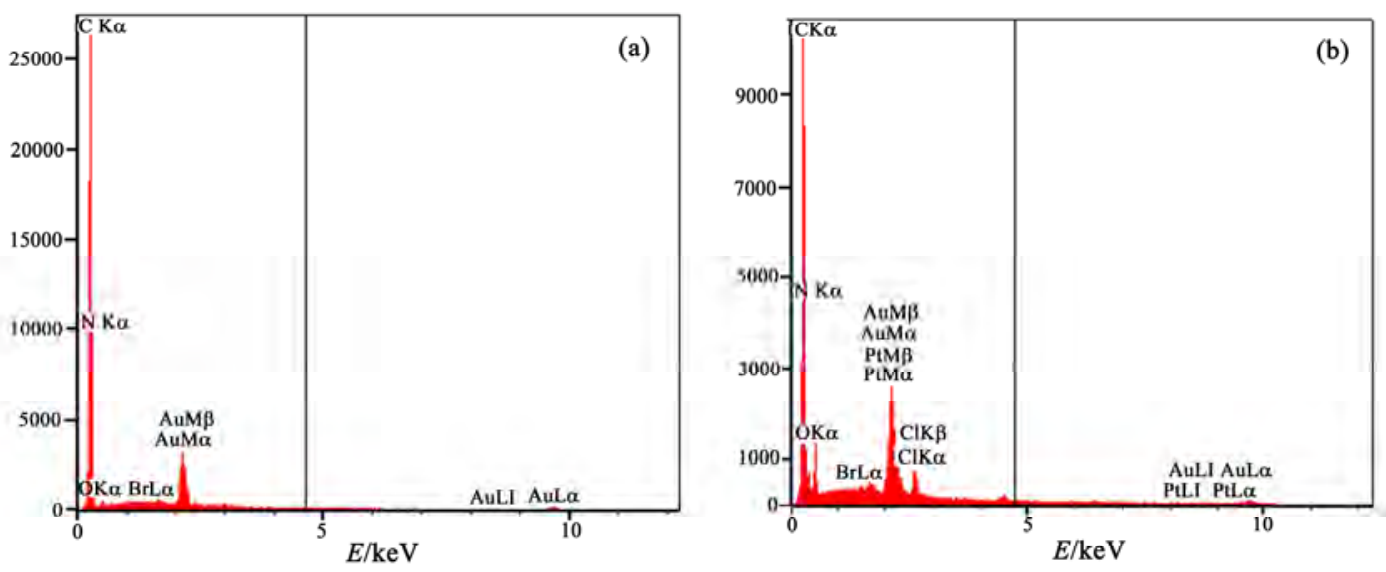

Fig. 3. ED spectra of (a) CTAB-GCE and (b) Pt/CTAB-GCE. 


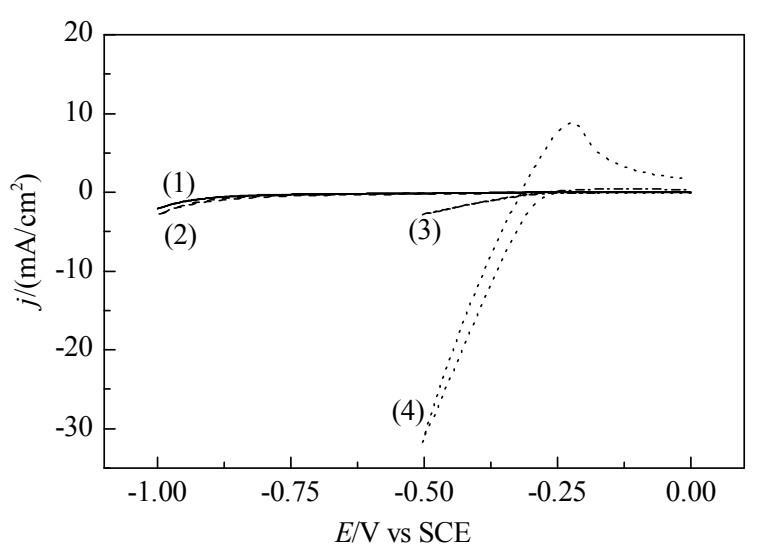

Fig. 4. Cyclic voltammograms for HER at surface of (1) bare GCE, (2) CTAB-GCE, (3) Pt/GCE, and (4) Pt/CTAB-GCE in $\mathrm{H}_{2} \mathrm{SO}_{4}$ solution $(0.1$ $\mathrm{mol} / \mathrm{L}$ ) at $v=50 \mathrm{mV} / \mathrm{s}$.

commonly used for specimen coating. The coating may increase the signal-to-noise ratios for samples of low atomic number. Electrochemical evidence of Pt deposition was also obtained by potential cycling of the electrode in $\mathrm{H}_{2} \mathrm{SO}_{4}$ solution.

\subsection{Electrocatalytic activity of Pt/CTAB-GCE in HER}

The electrocatalytic activity of the Pt/CTAB-GCE in the HER was studied in $\mathrm{H}_{2} \mathrm{SO}_{4}$ solution using cyclic voltammetry. Overlaid cyclic voltammograms of the HER at a bare GCE, CTAB-GCE, Pt/GCE, and Pt/CTAB-GCE are shown in Fig. 4. As this figure shows, the CTAB hydrophilic layer enhances the electrocatalytic activity in the HER (curve (2)). The CTAB surfactant can be adsorbed on the hydrophobic surface to form a surfactant film, which may alter the over-potential of the electrode reaction and influence the rate of electron transfer. Curve (3) shows the cyclic voltammogram of the Pt/GCE in the HER. As can be seen, the HER can be catalyzed at the electrode surface with a higher current density than those at the bare GCE and CTAB-GCE. For the Pt/CTAB-GCE, the onset potential of the HER occurs at about $-0.23 \mathrm{~V}$ vs the SCE, indicated by an increase in the cathodic current (curve (4)). The anodic peak in the backward sweep is attributed to the oxidation of molecular hydrogen. The HER follows the same sequence of reactions as that reported for a smooth polycrystalline Pt electrode $[10,21,22]$, in which the second reaction is the rate-determining step. The performance of this modified electrode in the HER is similar to those achieved in our recent work [17].

$$
\begin{gathered}
\mathrm{H}^{+}+\mathrm{e}^{-}+\mathrm{M} \rightarrow \mathrm{M}-\mathrm{H}_{\text {ads }} \\
2 \mathrm{M}-\mathrm{H}_{\mathrm{ads}} \rightarrow 2 \mathrm{M}+\mathrm{H}_{2}
\end{gathered}
$$

Kinetic analysis of HER was performed. A Tafel plot (Fig. 5) was constructed from the current density-potential data in voltammogram (4) in Fig. 4. The Tafel slope and exchange current density $\left(j_{0}\right)$ were calculated by least-squares analysis of the plot. The cathodic transfer coefficient $(\alpha)$ and $j_{0}$ were calculated to be 1.31 and $1.1 \times 10^{-4} \mathrm{~A} / \mathrm{cm}^{2}$, respectively.

\subsection{Effect of CTAB film thickness}

The CTAB film thickness was controlled by varying the

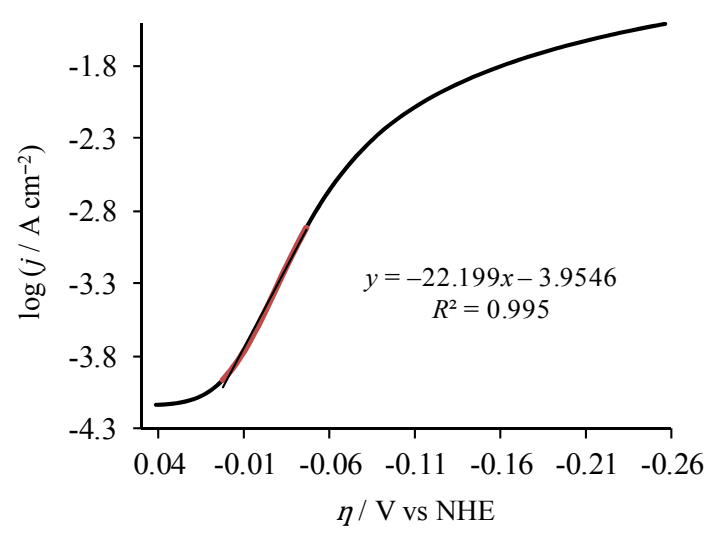

Fig. 5. Tafel plot for HER at Pt/CTAB-GCE in $\mathrm{H}_{2} \mathrm{SO}_{4}$ solution (0.1 mol/L).

$\mathrm{CTAB}$ concentration in the solution during preparation of the Pt/CTAB-GCE. The effect of the CTAB film thickness on the electrochemical response in the HER was investigated using CTAB concentrations from 1.0 to $5.0 \mathrm{mmol} / \mathrm{L}$ (Fig. 6). As Fig. 6 shows, as the CTAB concentration increased to $3.0 \mathrm{mmol} / \mathrm{L}$, the HER signal increased, but further increases in the film thickness (CTAB concentration $>3.0 \mathrm{mmol} / \mathrm{L}$ ) led to a decrease in the HER signal; $3.0 \mathrm{mmol} / \mathrm{L}$ was therefore the optimum CTAB concentration in this work.

\subsection{Long-term stability}

In practical application, the electrocatalytic activity and long-term stability of the electrode are important. The stability of the Pt/CTAB-GCE was checked by measuring the current density for HER over at least 15 cycles in $\mathrm{H}_{2} \mathrm{SO}_{4}$ solution $(0.1$ mol/L; Fig. 7(a)). The current density did not change significantly in consecutive potential scans. The Pt/CTAB-GCE therefore has good electrocatalytic activity, stability, and durability during HER. Figure 7(b) also shows the typical chronoamperometric response for a long time period at $-0.3 \mathrm{~V}$ vs the SCE in $\mathrm{H}_{2} \mathrm{SO}_{4}$ solution $(0.1 \mathrm{~mol} / \mathrm{L})$. As the figure shows, the current density does not drop significantly even after $2500 \mathrm{~s}$.

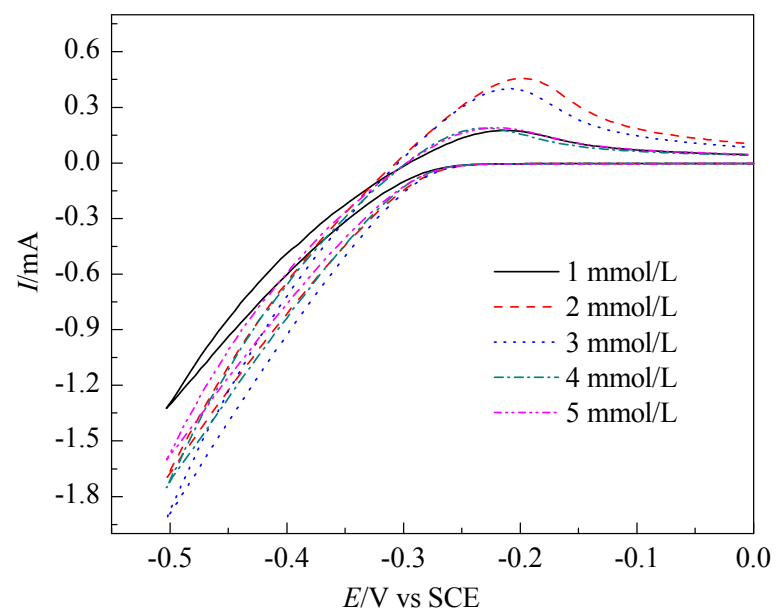

Fig. 6. Current-potential curves for Pt/CTAB-GCEs in $\mathrm{H}_{2} \mathrm{SO}_{4}$ solution $(0.1 \mathrm{~mol} / \mathrm{L})$ with different $\mathrm{CTAB}$ concentrations at $v=50 \mathrm{mV} / \mathrm{s}$. 

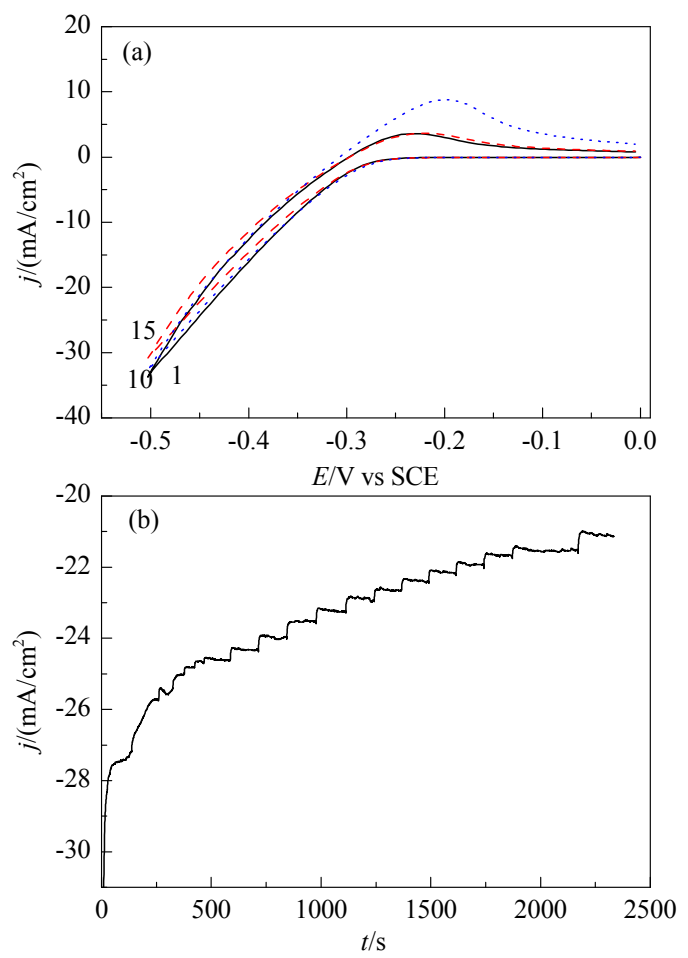

Fig. 7. (a) Cyclic voltammograms for Pt/CTAB-GCE in $\mathrm{H}_{2} \mathrm{SO}_{4}$ solution $(0.1 \mathrm{~mol} / \mathrm{L}) ; 1,10$, and 15 are the cycle numbers of the potential sweeps at $v=50 \mathrm{mV} / \mathrm{s}$. (b) Chronoamperogram for HER catalyzed by Pt/CTAB at $-0.3 \mathrm{~V}$ vs $\mathrm{SCE}$ in $\mathrm{H}_{2} \mathrm{SO}_{4}$ solution $(0.1 \mathrm{~mol} / \mathrm{L})$.

\section{Conclusions}

This paper describes a unique, simple, and rapid approach to preparing Pt microparticles on a solid electrode substrate using a two-step process. The results show that CTAB was adsorbed on the electrode surface. CTAB aggregates of average size less than $100 \mathrm{~nm}$ on the GCE surface had a positive influence on the HER as a result of increased electron-transfer rates. The electrocatalytic activity of the Pt/CTAB-GCE in the HER was compared with those of a bare GCE, CTAB-GCE, and Pt/GCE under the same conditions. The Pt/CTAB-GCE exhibited supe- rior electrocatalytic activity in the HER.

\section{Acknowledgments}

This work was supported by the University of Mazandaran.

\section{References}

[1] Hernandez F, Baltruschat H. J Solid State Electrochem, 2007, 11: 877

[2] Mentus S, Mojovic Z, Cvjeticanin N, Tesic Z. Fuel Cells, 2003, 3: 15

[3] Shibli S M A, Dilimon V S.J Solid State Electrochem, 2007, 11: 1119

[4] Torabi M, Dolati A. J Appl Electrochem, 2010, 40: 1941

[5] Sun L S, Ca D V, Cox J A. J Solid State Electrochem, 2005, 9: 816

[6] Pournaghi-Azar M H, Habibi B. J Electroanal Chem, 2007, 605: 136

[7] Stoychev D, Papoutsis A, Kelaidopoulou A, Kokkinidis G, Milchev A. Mater Chem Phys, 2001, 72: 360

[8] Yu E H, Scott K, Reeve R W, Yang L X, Allen R G. Electrochim Acta, 2004, 49: 2443

[9] Mahe E, Devilliers D, Groult H, Pouilleau J. Electrochim Acta, 1999, 44: 2307

[10] Habibi B, Pournaghi-Azar M H, Razmi H, Abdolmohammad-Zadeh H. Int J Hydrogen Energy, 2008, 33: 2668

[11] Hosseinzadeh R, Sabzi R E, Ghasemlu K. Colloids Surf B, 2009, 68: 213

[12] Ghaemi M, Khosravi-Fard L, Neshati J. J Power Sources, 2005, 141: 340

[13] Li C Y. Colloids Surf B, 2007, 55: 77

[14] Hu C G, Hu S S. Electrochim Acta, 2004, 49: 405

[15] He Q, Dang X P, Hu C G, Hu S S. Colloids Surf B, 2004, 35: 93

[16] Wang F, Fei J J, Hu S S. Colloids Surf B, 2004, 39: 95

[17] Raoof J B, Ojani R, Rashid-Nadimi S. J Electroanal Chem, 2010, 641: 71

[18] Raoof J B, Ojani R, Kiani A, Rashid-Nadimi S. Int J Hydrogen Energy, 2010, 35: 452

[19] Raoof J B, Ojani R, Asghari-Esfeden S, Rashid-Nadimi S. Int J Hydrogen Energy, 2010, 35: 3937

[20] Hegde R N, Kumara Swamy B E, Shetti N P, Nandibewoor S T. J Electroanal Chem, 2009, 635: 51

[21] Conway B E, Bai L J. J Electroanal Chem Interfacial Electrochem, 1986, 198: 149

[22] Parsons R. Trans Farady Soc, 1958, 54: 1053

\section{Graphical Abstract}

Chin. J. Catal., 2015, 36: 216-220 doi: 10.1016/S1872-2067(14)60207-2

Improved hydrogen evolution on glassy carbon electrode modified with novel Pt/cetyltrimethylammonium bromide nanoscale aggregates

Jahan-Bakhsh Raoof*, Sayed Reza Hosseini, Seyedeh Zeinab Mousavi-Sani

University of Mazandaran, Iran

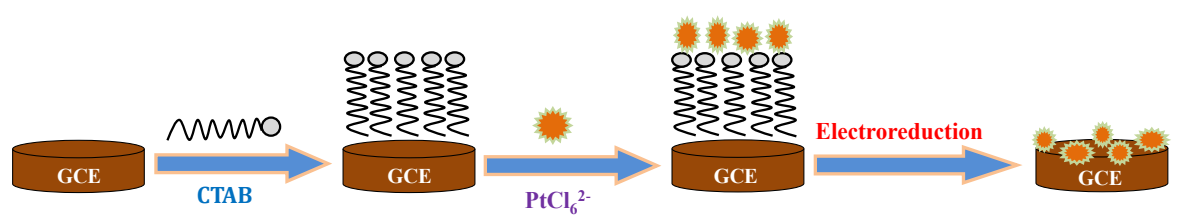

A novel, cost-effective, and simple electrocatalyst based on a Pt-modified glassy carbon electrode prepared using cetyltrimethylammonium bromide (CTAB) is reported. The results show that CTAB nanoaggregates enhance the electrocatalytic activity of the Pt microparticles in hydrogen evolution reaction. 